\title{
The olfactory bulbs in Alzheimer's disease
}

\author{
MARGARET M ESIRI, GORDON K WILCOCK \\ From the Departments of Neuropathology and Geriatric Medicine, The Radcliffe Infirmary, Oxford, UK
}

SUMMARY The olfactory bulbs have been examined in patients with Alzheimer's disease and compared with those in elderly undemented and younger undemented control patients. In Alzheimer's disease neurofibrillary tangles were found in the anterior olfactory nucleus but not elsewhere in the olfactory bulb. Cell loss in the anterior olfactory nucleus was also found in Alzheimer's disease. It is clear that the olfactory sensory pathway is pathologically affected in Alzheimer's disease and would merit further study.

Alzheimer's disease is characterised pathologically by the development of numerous argyophilic plaques and neurofibrillary tangles within the brain. Regions of the brain that are particularly severely affected in this disease include important parts of the olfactory system such as the uncus ${ }^{1}$ and the cortico-medial part of the amygdaloid nucleus. ${ }^{2} \mathrm{We}$ therefore decided to examine more peripheral parts of the olfactory sensory pathway. The olfactory bulbs and anterior olfactory nuclei have not to our knowledge been studied previously in Alzheimer's disease. Neurofibrillary tangles have been described in the olfactory bulbs of several cases of the Parkinsonism-dementia complex of Guam but not in Alzheimer's disease. ${ }^{3}$ We report here our observations on these structures in patients with Alzheimer's disease and in undemented young and elderly control patients.

\section{Materials and methods}

Pairs of olfactory bulbs from six patients with Alzheimer's disease, five undemented elderly $(>60 \mathrm{yrs})$ control patients, and five younger ( $<60$ yrs) control patients (see table), were removed from the necropsy brains after fixation in $10 \%$ neutral formalin, and embedded in paraffin wax. Patients included in the group with Alzheimer's disease had been prospectively assessed for dementia during life and had the diagnosis confirmed neuropathologically by demonstrating the presence of numerous neurofibrillary tangles and argyrophilic plaques in frontal and temporal lobe neocortex. The elderly control patients had also been assessed prospectively and the absence of intellectual impairment confirmed. The methods employed are dis-

Address for reprint requests: Dr M Esiri, Department of Neuropathology, The Radcliffe Infirmary, Woodstock Road, Oxford, OX2 6HE, UK.

Received 25 May 1983. Accepted 5 July 1983 cussed in detail elsewhere. ${ }^{4}$ Examination of their brains at necropsy had shown that neurofibrillary tangles were absent or were present in very small numbers in the hippocampus and parahippocampal gyrus only. The young undemented patients had died of acute subarachnoid and intracerebral haemorrhage associated with the presence of a ruptured berry aneurysm on a major cerebral artery.

Serial $10 \mu$ horizontal sections of the olfactory bulb were cut and the first and every following 30th section stained using Cross' modification of the Palmgren stain ${ }^{5}$ to demonstrate neurofibrillary tangles. A $20 \mu$ section immediately adjacent to each of these was stained with cresyl fast violet. Quantitative studies were made at a magnification of 320 on the anterior olfactory nuclei using a semi-automatic image analyser (Graphic Information Systems). Within the bulb the arrangement of the cells of the anterior olfactory nuclei precluded cell counting in random fields. In each case, therefore, the three fields which were judged by visual inspection to have the greatest cell density within the anterior olfactory nuclei were graded (on a scale of $0-3$ ) according to the number of neurofibrillary tangles present ( 0 = absence of tangle formation; $1=$ minimal; $2=$ moderate; 3 = severe). The two highest grades in each case were recorded for analysis. Cresyl fast violet-stained sections were used to perform neuron cell counts on the anterior olfactory nuclei at $\mathbf{3 2 0}$ magnification using a Weibel graticule and a point counting technique on five fields where cell density was judged by visual inspection to be highest. The three highest counts for each case were then used for the analysis. Cells were only counted if they were large $(>20 \mu)$ and the nucleus contained a prominent nucleolus.

\section{Results}

The several layers of the olfactory bulb were readily distinguishable in all three groups of patients studied though some distortion or irregularity of the cell layers was common in all groups. As described by Crosby $e t a l,{ }^{\circ}$ the neurons of the anterior olfactory nuclei were visible lying deep within the olfactory 

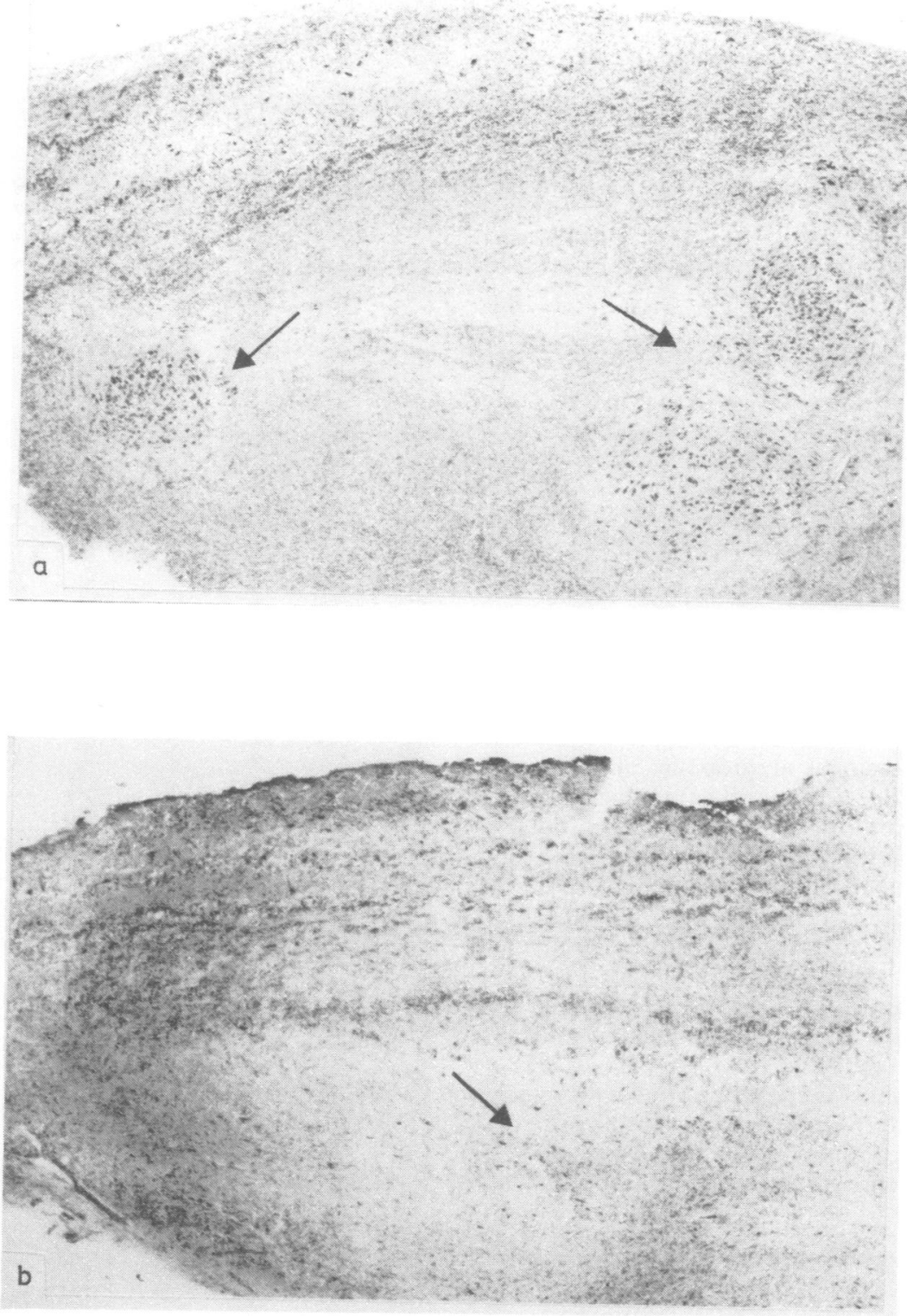

Fig 1 Low power view of olfactory bulb to show anterior olfactory nuclei neurons (arrows) from an elderly control patient $(A)$. Neurons have almost entirely disappeared from this nucleus from a patient with Alzheimer's disease $(B)$. Nissl stain $\times 50(A$ and $B)$. 


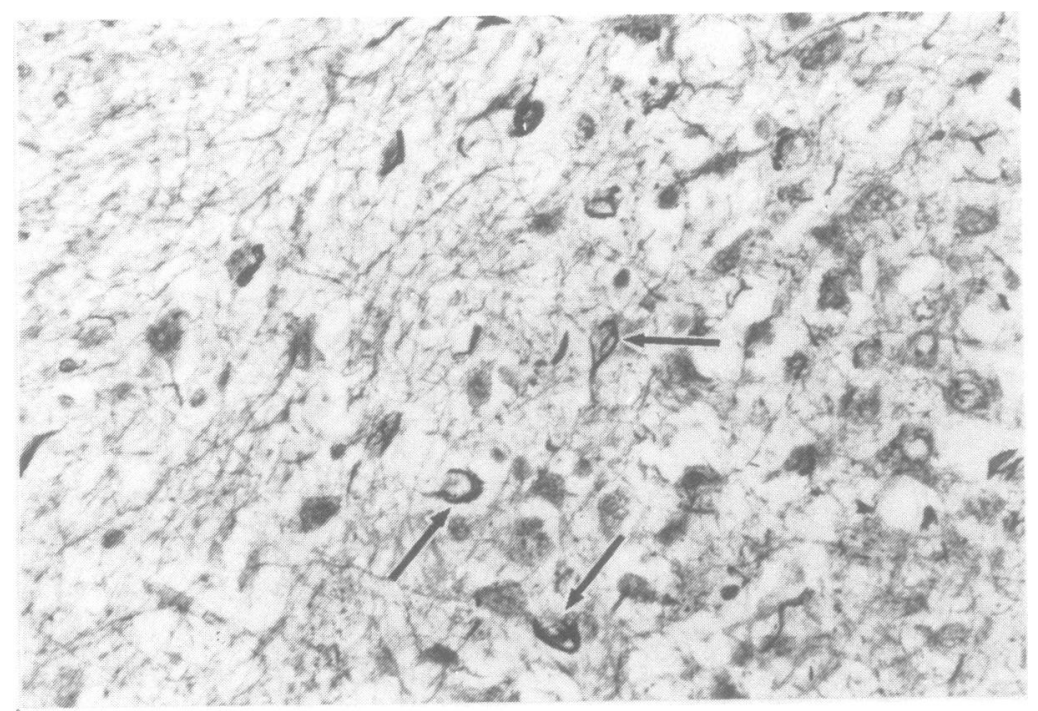

Fig 2 Anterior olfactory nucleus from a case of Alzheimer's disease. Neurofibrillary tangles present at arrows. Modified Palmgren stain $\times 500$.

bulb (fig 1A, B). In Alzheimer's disease, neurofibrillary tangles were frequently found within the neurons of the anterior olfactory nuclei but not within cells of the glomeruli, mitral cells or granule cells (fig 2). Occasional argyrophilic plaques were also seen within the anterior olfactory nuclei but not elsewhere. Neurofibrillary tangles were not found in the younger control patients and were rare and confined to the nucleus in the elderly controls (table). In the latter the grades recorded in the 10 fields were all 0 to 1 , whilst in the demented patients, in only three fields was a grade of 0 or 1 recorded, the majority of fields (9) being graded 2 or 3 . This difference is statistically significant $(p<$ 0.01: Fisher's Exact Test).

Neuron cell counts in the anterior olfactory nuclei were substantially reduced in the Alzheimer's disease patients as compared with controls (fig $3 \mathrm{~A}, \mathrm{~B}$ ).

Table

\begin{tabular}{lccc}
\hline & $A D$ & $\begin{array}{l}\text { Elderly } \\
\text { controls }\end{array}$ & $\begin{array}{l}\text { Young } \\
\text { controls }\end{array}$ \\
\hline $\begin{array}{l}\text { No. of patients } \\
\text { Mean age } \\
\text { (range) }\end{array}$ & 6 & $5^{*}$ & 5 \\
$\begin{array}{l}\text { Neuro fibrillary } \\
\text { tangles-mean }\end{array}$ & $(64-91 \mathrm{yr})$ & $\begin{array}{c}81 \\
(65-91 \mathrm{yr})\end{array}$ & $\begin{array}{c}39 \\
(19-54)\end{array}$ \\
$\begin{array}{l}\text { grade } \\
\text { (sd) }\end{array}$ & 1.92 & $0 \cdot 50$ & \\
$\begin{array}{l}\text { Cell counts } \\
\text { (sd) }\end{array}$ & $\begin{array}{l}(1 \cdot 1) \\
(7.9)\end{array}$ & $\begin{array}{l}(0 \cdot 53) \\
41\end{array}$ & $0 \cdot 0$ \\
\hline
\end{tabular}

${ }^{*}$ Only 4 cases were suitable for cell counting.

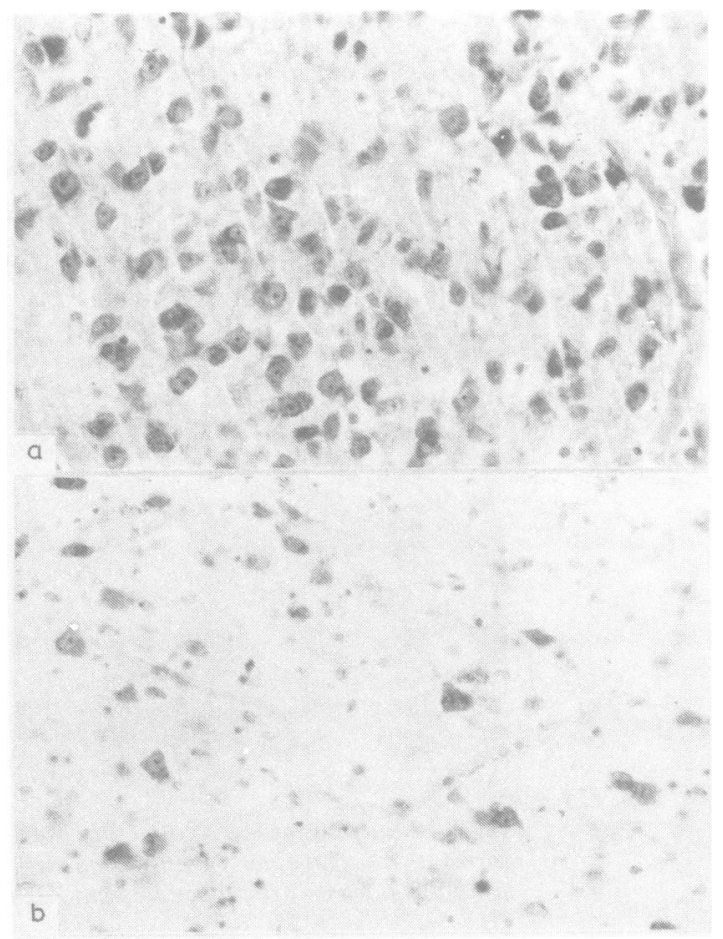

Fig 3. Anterior olfactory.nucleus from $(A)$ an elderly control patient, $(B)$ a case of Alzheimer's disease, to demonstrate reduced cell density in Alzheimer's disease. -Nissl stain $\times 330$. 
The anterior olfactory nuclei cell counts in elderly control patients were similar to those of young control patients but in Alzheimer's disease the counts were reduced to two thirds of the control value (table). The difference between the anterior olfactory nuclei cell counts in Alzheimer's disease, and elderly controls, was statistically significant using Student's $t$ test $(\mathrm{t}=5.34, \mathrm{df}=28, \mathrm{p}<0.001)$. Non-specific degenerative features, particularly the presence of numerous corpora amylacea, were evident in the olfactory bulb from elderly controls as well as in those from patients with Alzheimer's disease.

\section{Discussion}

The anterior olfactory nuclei has received very little study in humans. It is of some interest to note that animal studies stress the similarity of pyramidal type neurons of the anterior olfactory nuclei to those of the neocortex in terms of their general structure and organisation. ${ }^{7}$ These are the neurons in which neurofibrillary tangles were found in this study and similar neurons in the neocortex are likewise liable to develop neurofibrillary tangles in Alzheimer's disease. Both the anterior olfactory nuclei and neocortex have connections principally with ipsilateral and contralateral cortex. There are also interesting parallels between the anterior olfactory nuclei and the nucleus basalis in Alzheimer's disease, since neurofibrillary tangle formation and cell loss occur in both these nuclei. ${ }^{38-10}$ Large neurons of the nucleus basalis are thought to be cholinergic. ${ }^{112}$ On the other hand in the rat large neurons in the anterior olfactory nuclei do not react positively on immunohistological staining with an antibody to choline acetyltransferase, suggesting that they are not cholinergic (MV Sofraniew, personal communication).

The method of grading the number of neurofibrillary tangles in the nuclei was relatively crude, as are most grading systems relying on visual inspection rather than actual counts. Each case was graded on two separate occasions, without the observer being aware of the diagnosis. On both occasions the grades obtained were reasonably consistent, the only differences recorded were: a single field in each of two intellectually normal elderly controls graded 1 rather than 0 on the second assessment, and a single field in one of the Alzheimer's disease cases graded 3 rather than 2 . These changes would not have affected the statistical significance of the differences observed.

Neurofibrillary tangles were assessed in the fields with greatest cell density, as we were unable to count neurons in random fields, and it was consi- dered possible that the presence of tangles may be associated with death and loss of affected cells, resulting in an underestimate of the severity of tangle formation. It is interesting to note, however, that the fields with the greatest cell density also appeared to be those most severely afflicted by tangle formation.

The demonstration of significant neurofibrillary tangles formation and cell loss in the anterior olfactory nuclei in Alzheimer's disease suggests that further studies of the olfactory bulbs and anterior olfactory nuclei in Alzheimer's disease would be of value. The relative simplicity of the anatomy of the olfactory bulbs and anterior olfactory nuclei in comparison with the cerebral cortex, hippocampus and other sites at which neurofibrillary tangles develop in Alzheimer's disease, and the precise localisation of the pathology to the anterior olfactory nuclei, with sparing of the neurons of the olfactory bulb itself, may enable factors involved in the formation of neurofibrillary tangles to be defined. It is clear that the olfactory sensory pathway is significantly affected pathologically in Alzheimer's disease. The possible clinical significance of this observation remains to be explored.

We are grateful to Mr Rowland Cross for technical assistance, and Drs TPS Powell, RCA Pearson and JC Sloper for stimulating discussion and encouragement. This study was supported by a grant from the Oxfordshire Regional Research Fund, and the Joseph Senior White Research Fellowship of the Royal College of Physicians.

\section{References}

' Corsellis JAN. Chapter 18-Aging and the Dementias. In: Blackwood W, Corsellis JAN, eds. Greenfield's Neuropathology. London: Edward Arnold 1976: 796-848.

${ }^{2}$ Hertzog AG, Kemper TL. Amygdaloid changes in aging and dementia. Arch Neurol 1980;37:625-9.

${ }^{3}$ Hirano A, Zimmerman HM. Alzheimer neurofibrillary changes, a topographic study. Arch Neurol 1962; 7:227-42.

4 Wilcock GK, Esiri MM. Plaques, tangles and dementia, a quantitative study. J Neurol Sci 1982;56:343-56.

5 Cross RD. Demonstration of neurofibrillary tangles in paraffin sections-with a simple method using a modification of Palmgren's method. Med Lab Sci 1982;39:67-9.

${ }^{6}$ Crosby EC, Humphrey T, Lauer EW. Correlative anatomy of the nervous system. New York: Macmillan, 1962:416-18.

${ }^{7}$ Haberly LB, Price JL. Association and commissural fiber systems of the olfactory cortex of the rat. II systems 
originating in the olfactory peduncle. J Comp Neurol 1978;181:781-808.

${ }^{8}$ Ishii T. Distribution of Alzheimer neurofibrillary changes in the brain stem and hypothalamus of senile dementia. Acta Neuropathol (Ber) 1966;6:181-7.

${ }^{9}$ Whitehouse PJ, Price DL, Clark AW, Coyle JT, Delong MR. Alzheimer's disease: evidence for selective loss of cholinergic neurones in the nucleus basalis. Ann Neurol 1981;10:122-6.

${ }^{10}$ Wilcock GK, Esiri MM, Bowen DM, Smith CCT. The nucleus basalis in Alzheimer's disease: Cell counts and cortical biochemistry. Neuropath Appl Neurobiol. 1983; 9:175-9.

"Mesulam MM, Van Hoesen GW. Acetylcholinesteraserich projections from the basal forebrain of the rhesus monkey to neocortex. Brain Res 1976;109:152-7.

12 Parent A, Poirier LJ, Boucher R, Butcher LL. Morphological characteristics of acetylcholinesterase-containing neurones in the CNS of DFP treated monkeys. J Neurol Sci 1977;32:9-28. 